\title{
An Economic Study of the Demand Function for Wheat Imports in Egypt
}

\author{
Nagwa M. El-Agroudy, Fatima A. Shafiq, Soheir Mokhtar and, Monia B. El-Din Hassan \\ Department of Agricultural Economy, Agricultural and Biological Research Division, National \\ Research Centre, 33 El Buhouth St., 12622 Dokki, Giza, Egypt \\ Received: 12 May 2020/ Accepted 08 July 2020 / Publication date: 20 July 2020
}

\begin{abstract}
The wheat crop is one of the most important strategic food grain crops in Egypt. Besides, it is considered the main food for all classes of the Egyptian people, especially those with limited income. It is used in the bread loaf industry in addition to the dependence of many food industries on wheat and its flour. The problem is that the local production of wheat crop is unable to meet local consumption. The ratio of its self-sufficiency reached $42 \%$. In order to fill this gap, the country resorts to import from abroad by about 2432 million dollars in 2018. Moreover, the study aims to show the development of the productive situation of the wheat crop, the development of the food gap of the wheat crop and some factors affecting it in Egypt. This is in addition to estimating the self-sufficiency ratio, the quantity, and value of imports during the period and studying the demand function for wheat imports and the food security factor of wheat. Besides, the study used both descriptive and quantitative analysis to study the previous factors

.Consequently, the study showed an increase in the total production, total consumption and average per capita with a statistically significant increase of about $160.2,507.57$ thousand tons, 1,41 $\mathrm{kg}$, respectively. This is in addition to the increase in the size of the gap, the amount of imports and the stock size with a statistically significant increase estimated at 316.72, 402.43, 222.97 thousand tons annually, respectively. Moreover, the value of imports increased with a statistically significant increase during the study period by about 134.93 million dollars.

By estimating the function of the demand for imports of wheat using the logarithmic state, it became obviously clear that the most important determinants of the quantities imported from wheat are the population, the amount of consumption, and the amount of production. It is important to mention in this context that it has been proven that there is a direct relationship between the population and the quantity of imports and an inverse relationship between the quantity of production and both consumption and production. Besides, by estimating the food security coefficient of wheat, it turned out to be about -0.051 . This indicates that the value of the food security coefficient is less than zero, which reflects the food insecurity situation of wheat. Therefore, it is necessary to work with the relevant state agencies to increase the food security factor of wheat. This can be done by expanding its cultivation and working to raise its productivity. This is in addition to find a fair price for farmers to encourage its cultivation and supply to the state and attention to rationalizing consumption and finding appropriate alternatives, in order to create an accumulation in the strategic stock that is sufficient for local consumption to achieve food security of wheat in Egypt.
\end{abstract}

Keywords: Wheat, Demand Function, Food Security Factor

\section{Introduction}

The wheat crop is one of the most important strategic food grain crops in Egypt. Besides, it is considered the main food for all classes of the Egyptian people, especially those with limited income. It is used in the bread loaf industry in addition to the dependence of many food industries on wheat and its flour. Moreover, the demand for it is conspicuously increasing, especially with the steady population increase and the limited resources in Egypt. Egypt suffers from a continuous gap in this crop. It is noteworthy that increasing production, whether by vertical and horizontal expansion, consumption rationalization, and reducing losses, is the way to increase the self- sufficiency and reducing its food gap. Additionally, the wheat crop is considered one of the most important commodities of agricultural food imports.

Corresponding Author: Nagwa M. El-Agroudy, Field Crops Research Dept., National Research Centre, 33 El Buhouth St., 12622 Dokki, Giza, Egypt. E-mail: nagwa_agroudy@hotmail.com 


\section{Problem of the Study}

The problem is that the local production of wheat crop is unable to meet local consumption. The ratio of its self-sufficiency reached $42 \%$ in 2018 . Consequently, the result is a food gap from the wheat crop. In order to fill this gap, the country resorts to import from abroad. The value of wheat imports is estimated at about 2.43 billion Egyptian pound in 2018. Thus, it may increase the burden on the balance of payments. This necessitates studying the current situation of the wheat crop in Egypt and various ways to reduce its food gap.

\section{Objective of the Study}

Here is a statement of the development of the productive situation of the wheat crop, the development of the food gap of the wheat crop and some factors affecting it in Egypt. This is in addition to estimating the self-sufficiency ratio, the quantity, and value of imports during the period (2000 2018), and studying the demand function for wheat imports and the food security factor of wheat.

\section{Methodology and Data Sources of the Study}

The study used the descriptive analysis approach in describing the problem. This is in addition to the quantitative analysis using some different measurements such as the general trend that was used in studying the development of some productive and consumer indicators of wheat, as well as the multiple regression in its double logarithmic state to estimate the demand function for wheat imports in Egypt. Moreover, the study relied on secondary data collected from the Central Agency for Public Mobilization and Statistics, the Ministry of Agriculture and Land Reclamation as well as the secondary data published on the websites of the international networks of information.

\section{Economic Indicators of Wheat Crop in Egypt \\ Total Production}

Table (1) shows an increase in wheat production from about 6255 thousand tons in 2001, as a minimum, to about 9608 thousand tons in 2015 as a maximum. The increase in production is with a statistically significant annual increase by about 160.2 thousand tons. Table (2) shows an increase by about $1.99 \%$ of the average of about 8054 thousand tons. This increase is mainly due to the increase the area during the study period 2000-2018.

\section{Total Consumption}

Table (1) data indicates an increase in the total consumption of wheat by about 9819 thousand tons in 2001, as a minimum, to about 19975 thousand tons, as a maximum, in 2018. This was with a statistically significant annual increase of a total of about 507.75 thousand tons per year and a growth rate of about $3.41 \%$ of the annual average that was about 14887 million tons as shown in Table (2). This is due to the high population in the first place. Besides, we have the consumer preference for wheat crop as a food pattern for the majority of the Egyptian people. Moreover, there is the expansion of the food industry, which depends on the wheat crop and its products as a raw material.

\section{Average per Capita}

Table (1) shows that the average per capita share of wheat ranged between a minimum of about $163 \mathrm{~kg} /$ year in the year 2000, and a maximum of about $186 \mathrm{~kg}$ / year in 2015 , with an average period of study by about (175.92 kg). Table (2) shows that the increase of annual average per capita of wheat with a statistically significant increase by about $1.41 \mathrm{~km} 1$. It is equivalent to about $0.80 \%$ of the average of about $175.92 \mathrm{~kg} /$ year during the study period (2000-2018).

\section{Size of the Wheat Gap}

Table (1) shows an increase in the gap size of wheat crop from about 3564 thousand tons in 2001 as a minimum to about 10092 thousand tons in 2018 as a maximum during the study period. Besides, Table (2) shows an increase in the gap size of wheat crop by about 316.72 thousand tons per year. It is equivalent to about $4.38 \%$ of the average of about 7224 thousand tons. 
Table 1: Economic Indicators of Wheat Crop in Egypt during the Period (2000-2018)

\begin{tabular}{ccccc}
\hline Year & $\begin{array}{c}\text { Total Production } \\
\text { (Thousand Tons) }\end{array}$ & $\begin{array}{c}\text { Available for } \\
\text { Consumption } \\
\text { (Thousand Tons) }\end{array}$ & $\begin{array}{c}\text { Share Per } \\
\text { Capita / kg }\end{array}$ & Self-sufficiency \% \\
\hline $\mathbf{2 0 0 0}$ & 6564 & 11114 & 163.0 & 59.1 \\
$\mathbf{2 0 0 1}$ & 6255 & 9819 & 165.2 & 63.7 \\
$\mathbf{2 0 0 2}$ & 6625 & 11625 & 169.0 & 57.0 \\
$\mathbf{2 0 0 3}$ & 6845 & 10936 & 167.1 & 62.6 \\
$\mathbf{2 0 0 4}$ & 7178 & 11754 & 166.7 & 61.1 \\
$\mathbf{2 0 0 5}$ & 8141 & 13353 & 165.0 & 61.0 \\
$\mathbf{2 0 0 6}$ & 8274 & 14257 & 167.2 & 58.0 \\
$\mathbf{2 0 0 7}$ & 7379 & 13773 & 170.2 & 53.6 \\
$\mathbf{2 0 0 8}$ & 7977 & 14546 & 177.0 & 54.8 \\
$\mathbf{2 0 0 9}$ & 8523 & 14592 & 181.9 & 58.4 \\
$\mathbf{2 0 1 0}$ & 7169 & 14978 & 180.4 & 47.9 \\
$\mathbf{2 0 1 1}$ & 8370 & 16878 & 182.2 & 49.6 \\
$\mathbf{2 0 1 2}$ & 8795 & 15657 & 183.7 & 56.2 \\
$\mathbf{2 0 1 3}$ & 9460 & 17210 & 179.7 & 55.0 \\
$\mathbf{2 0 1 4}$ & 9280 & 17025 & 182.3 & 54.5 \\
$\mathbf{2 0 1 5}$ & 9608 & 17800 & 186.0 & 54.0 \\
$\mathbf{2 0 1 6}$ & 9355 & 18000 & 184.1 & 52.0 \\
$\mathbf{2 0 1 7}$ & 8770 & 18723 & 185.9 & 45.0 \\
$\mathbf{2 0 1 8}$ & 8450 & 19975 & 186.0 & 42.0 \\
Average & 8054 & 14887 & 175.92 & 55.2 \\
\hline
\end{tabular}

Table 1: Continued

\begin{tabular}{ccccc}
\hline Year & $\begin{array}{c}\text { Wheat Gap } \\
\text { (Thousand Tons) }\end{array}$ & $\begin{array}{c}\text { Amount of Imports } \\
\text { (Thousand Tons) }\end{array}$ & $\begin{array}{c}\text { Value of } \\
\text { Imports } \\
\text { (Million } \\
\text { Dollars) }\end{array}$ & $\begin{array}{c}\text { Stock (Thousand } \\
\text { Tons) }\end{array}$ \\
\hline $\mathbf{2 0 0 0}$ & 4550 & 4896 & 713 & 1910 \\
$\mathbf{2 0 0 1}$ & 3564 & 4413 & 667 & 1795 \\
$\mathbf{2 0 0 2}$ & 5000 & 5575 & 816 & 1532 \\
$\mathbf{2 0 0 3}$ & 4091 & 4057 & 607 & 1254 \\
$\mathbf{2 0 0 4}$ & 4576 & 4367 & 728 & 1977 \\
$\mathbf{2 0 0 5}$ & 5212 & 5688 & 3258 \\
$\mathbf{2 0 0 6}$ & 5983 & 8004 & 924 & 4011 \\
$\mathbf{2 0 0 7}$ & 6395 & 8242 & 2168 & 4208 \\
$\mathbf{2 0 0 8}$ & 6569 & 8328 & 4566 \\
$\mathbf{2 0 0 9}$ & 6069 & 9121 & 5231 \\
$\mathbf{2 0 1 0}$ & 7809 & 10594 & 2570 & 5557 \\
$\mathbf{2 0 1 1}$ & 8508 & 9800 & 2598 & 6113 \\
$\mathbf{2 0 1 2}$ & 6862 & 8300 & 3331 & 5918 \\
$\mathbf{2 0 1 3}$ & 7750 & 10170 & 2511 & 6710 \\
$\mathbf{2 0 1 4}$ & 7745 & 9423 & 3139 & 7148 \\
$\mathbf{2 0 1 5}$ & 8192 & 9686 & 2994 & 4336 \\
$\mathbf{2 0 1 6}$ & 8645 & 10788 & 2569 & 4052 \\
$\mathbf{2 0 1 7}$ & 9368 & 11026 & 2254 & 3902 \\
$\mathbf{2 0 1 8}$ & 10092 & 11200 & 2355 & 4568 \\
Average & 7224 & 8088 & 2432 & 1910 \\
\hline
\end{tabular}

Source:

- Ministry of Agriculture and Land Reclamation - Economic Affairs Sector - Agricultural Economics Publications - Various Issues

- Central Agency for Public Mobilization and Statistics - Annual Statistical Book - Various Issues 
Table 2: Equations of the General Time Trend of Economic Indicators of Wheat in Egypt during the Period (2000-2018)

\begin{tabular}{llccc}
\hline Indicator & \multicolumn{1}{c}{ Equation } & $\mathbf{R}^{\mathbf{2}}$ & $\mathbf{F}$ & $\mathbf{T}$ \\
\hline Production (Thousand Tons) & $\mathrm{Y}^{\wedge}=6451.74+160.18 \mathrm{xi}$ & 0.726 & 44.973 & $6.706^{* *}$ \\
Consumption (Thousand Tons) & $\mathrm{Y}^{\wedge}=9765.44++507.75 \mathrm{xi}$ & 0.958 & 383.933 & $19.594^{* *}$ \\
Share Per Capita (kg / Year) & $\mathrm{Y}^{\wedge}=161.80+1.41 \mathrm{xi}$ & 0.874 & 117.821 & $10.855^{* *}$ \\
Self-sufficiency \% & $\mathrm{Y}^{\wedge}=63.22-0.82 \mathrm{xi}$ & 0.628 & 28.702 & $-5.357^{* *}$ \\
Wheat Gap (Thousand Tons) & $\mathrm{Y}^{\wedge}=3515.95+316.72 \mathrm{xi}$ & 0.904 & 161.111 & $12.653^{* *}$ \\
Amount of Imports (Thousand Tons) & $\mathrm{Y}^{\wedge}=4064.05+402.43 \mathrm{xi}$ & 0.853 & 86.020 & $9.257^{* *}$ \\
Value of Imports (Thousand Tons) & $\mathrm{Y}^{\wedge}=608.49+134.93 \mathrm{xi}$ & 0.654 & 32.193 & $5.674^{* *}$ \\
Stock (Thousand Tons) & $\mathrm{Y}^{\wedge}=1877.95+222.97 \mathrm{xi}$ & 0.493 & 16.559 & $4.669^{* *}$ \\
\hline
\end{tabular}

Where $\mathrm{Y}^{\wedge}$ indicates the estimated value of the dependent variable.

$\mathrm{X}_{\mathrm{i}}$ denotes the time element as an independent variable where ${ }_{\mathrm{i}}(1,2,3,4 \ldots 19)$

** Significant at the level of $1 \%$.

Source: Calculated from Table (1) .

\section{Import Quantity}

Table (1) shows an increase in the amount of imports of wheat crop from about 4057 thousand tons in 2003, as a minimum, to about 11200 thousand tons in 2018, as a maximum, during the study period. Besides, Table No. (2) Shows a statistically significant increase in the amount of imports by about 402.43 thousand tons per year. It is equivalent to about $4.98 \%$ of the average of 8088 thousand tons.

\section{Import Value}

Table (1) conspicuously shows an increase in the value of imports of wheat crop from about 607 thousand tons in 2003, as a minimum, to about 3331 million dollars in 2011, as a maximum, during the study period. Moreover, Table (2) shows a statistically significant increase in the value of imports by about 134.93 million dollars annually. It is equivalent to about $6.87 \%$ of the average of about 1963 million dollar.

\section{Stock Size}

Table (1) shows an increase in the volume of the wheat crop from about 1254 thousand tons in 2003 , as a minimum, to about 7148 tons in 2014, as a maximum, during the study period. Besides, Table (2) shows a statistically significant increase in -the volume of stock by about 222.97 thousand tons per year. It is equivalent to about $11.67 \%$ of the average of about 1910 thousand tons.

\section{Statistical Estimation of the Demand Function for Wheat Imports in Egypt}

Through studying the relationship between the amount of wheat imports at the national level as a dependent variable, and the most important explanatory factors whose effect on this dependent variable is believed to be represented in (production, consumption, stock size, price per ton of imports, population) during the period (2018-2001) .

It turns out that the most appropriate mathematical formula expressing this relationship is (Stepwise), which can be written in the following form:

$$
\begin{aligned}
& \mathrm{LnY}=0.010+1.538 \operatorname{Ln} \mathrm{X} 6-0.282 \operatorname{Ln} \mathrm{X} 3-0.904 \operatorname{Ln} \mathrm{X} 1 \\
& (6.001)^{* *} \quad(3.757)^{* *} \quad(-2.452)^{* *} \\
& \mathrm{~F}=75.123
\end{aligned}
$$

Whereas:

$\mathrm{Y}=$ wheat imports by thousand tons

$\mathrm{X} 1=$ the amount of wheat production by thousand tons

$\mathrm{X} 3=$ wheat consumption by thousand tons

$\mathrm{X} 6=$ population by million people

The results of this model conspicuously indicate that the most important determinants of imported quantities of wheat are population, consumption, and amount of production.

The value of the determining factor for the estimated model was about 0.938 , which means that about $93.8 \%$ of the changes that occur in the quantity of wheat imports are due to the change in these 
independent variables. Moreover, the model shows that there is a direct relationship between the population and the amount of imports. With a population increase of $1 \%$, the amount of imports increases by $1.538 \%$. Besides, the results indicate an inverse relationship between the consumption of wheat and the amount of imports as an increase of the variable by $1 \%$ leads to a decrease in the amount of imports by $0.282 \%$. There is also an inverse relationship between the amount of wheat production and the amount of imports as an increase of a variable by $1 \%$ leads to a decrease in the amount of imports by $0.904 \%$.

\section{Food Security Coefficient:}

By estimating the food security coefficient of wheat, as a ratio between the sum of the strategic stock size of about 1910 thousand tons to the annual local consumption average estimated at 14887 thousand tons, or as a ratio between the annual change in the volume of the strategic stock to the annual local consumption. It turned out to be about - 0.051 . This indicates that the value of the food security factor is less than zero, which reflects the food insecurity situation of wheat. Therefore, it is necessary to work with the relevant state agencies to increase the food security factor of wheat. This can be done by expanding its cultivation and working to raise its productivity. This is in addition to find a fair price for farmers to encourage its cultivation and supply to the state and attention to rationalizing consumption and finding appropriate alternatives, in order to create an accumulation in the strategic stock that is sufficient for local consumption to achieve food security of wheat in Egypt as shown in Table (3).

Table 3: Strategic Stock and Food Security Coefficient for Wheat during the Period (2000-2018)

\begin{tabular}{ccccc}
\hline Years & $\begin{array}{c}\text { Stock Size } \\
\text { (Thousand Tons) }\end{array}$ & $\begin{array}{c}\text { Stock Change } \\
\text { (Thousand Tons) }\end{array}$ & $\begin{array}{c}\text { Available for } \\
\text { Consumption } \\
\text { (Thousand Tons) }\end{array}$ & $\begin{array}{c}\text { Food Security } \\
\text { Coefficient* }\end{array}$ \\
\hline $\mathbf{2 0 0 0}$ & 1910 & - & - & - \\
$\mathbf{2 0 0 1}$ & 1795 & -115 & 9819 & -0.012 \\
$\mathbf{2 0 0 2}$ & 1532 & -263 & 11625 & -0.022 \\
$\mathbf{2 0 0 3}$ & 1254 & -278 & 10936 & -.025 \\
$\mathbf{2 0 0 4}$ & 1977 & 723 & 11754 & 0.062 \\
$\mathbf{2 0 0 5}$ & 3258 & 1281 & 13353 & 0.096 \\
$\mathbf{2 0 0 6}$ & 4011 & 753 & 14257 & 0,053 \\
$\mathbf{2 0 0 7}$ & 4208 & 197 & 13773 & 0,014 \\
$\mathbf{2 0 0 8}$ & 4566 & 358 & 14546 & 0.025 \\
$\mathbf{2 0 0 9}$ & 5231 & 665 & 14592 & 0.046 \\
$\mathbf{2 0 1 0}$ & 5557 & 326 & 14978 & 0.022 \\
$\mathbf{2 0 1 1}$ & 6113 & 556 & 16878 & 0.033 \\
$\mathbf{2 0 1 2}$ & 5918 & -195 & 15657 & -0.012 \\
$\mathbf{2 0 1 3}$ & 6710 & 792 & 17210 & 0.046 \\
$\mathbf{2 0 1 4}$ & 7148 & 438 & 17025 & 0.026 \\
$\mathbf{2 0 1 5}$ & 4336 & -2812 & 17800 & -0.158 \\
$\mathbf{2 0 1 6}$ & 4052 & -284 & 18000 & -0.0158 \\
$\mathbf{2 0 1 7}$ & 3902 & -150 & 19558 & -0.008 \\
$\mathbf{2 0 1 8}$ & 4568 & 666 & 19975 & 0.0333 \\
Average & 1910 & -762 & 14887 & -0.051 \\
\hline
\end{tabular}

$(*)$ The ratio of Stock Change to consumption.of production.

Source: Collected and calculated from Table No. (1)

\section{References}

Adel Mohamed Abdel-Wahhab Saleh (Ph.D.) - Mohamed Hassan Ahmed Ali (Ph.D.), 2018. An Analytical Economic Study to Reduce the Wheat Gap in Egypt - The Egyptian Journal of Agricultural Economics $-28^{\text {th }}$ Vol. $3^{\text {rd }}$ Edition, September.

Abdul Salam Jumaa (Ph.D.), 2004. A Wheat Production Vision, A Research Paper submitted to the $12^{\text {th }}$ Conference of Agricultural Economists, Cairo, (29-30) September.

Central Agency for Public Mobilization and Statistics - Annual Statistical Book - Various Issues.

Sarhan Ahmed Suleiman (Ph.D.), Nuran Abdel-Hamid Abdel-Jawad (Ph.D.), 2017."Security Assessment of Food Grain Crops in Egypt. The Egyptian Association for the Agricultural 
Economy, the $25^{\text {th }}$ Conference of Agricultural Economists, "Food Future in Egypt: Aspiration and Reality, (1 - 2), November.

The Ministry of Agriculture and Land Reclamation - Economic Affairs Sector - Agricultural Economics Publications - Various Issues

World Bank - The Economics of Project Analysis - Washington DC `1991 - Page, 220. 